\title{
Staphylococcus Saprophyticus Infection As A Cause Of Uti In Female Adolescents In Enugu Area, Nigeria
}

\author{
By Onyemelukwe, NF and NWOKOCHA, ARC
}

\begin{abstract}
This study was designed to determine whether Staphylococcus saprophyticus was an important cause of urinary tract infection (UTI), in Enugu area of Eastern Nigeria, as has been reported for Europe and N. America. S. saprophyticus was the second most frequent cause of UTI in young female adolescent (mean age of 23years) outpatients who are otherwise healthy, with an incidence rate of $27.4 \%$ as against matching group of in-patients (4\%) where it was the least encountered bacterial agent. Most cases presented with acute cystitis. The organism was rarely found as a cause of UTI in debilitating in-patients. A clear seasonality pattern favoring rainy season (75\%) as against the dry season of the year (25\%) was observed. The exact reason behind the seasonality pattern and the preponderance of $S$. saprophyticus in the out-patient of this population is not clear and requires further investigation. The results however show that S. saprophyticus should be included as an important uropathogen in female adolescents and young adult females in the area.
\end{abstract}

Keywords: adolescent females, Staphylococcus saprophyticus infection, UTI

\section{Introduction}

For a long time, coagulase negative staphylococci have been considered of little or no significance as a cause of urinary tract infection (UTI). However, from the seventies, a particular sub-group of coagulasenegative staphylococci, S. saprophyticus, was shown to be an important cause of UTI, first in Europe then followed by studies in the United States of America and Canada ${ }^{1}$. They were mainly found in young women ${ }^{2-4}$. In such works, it was reported that Staphylococcus saprophyticus was the second most common cause of UTI in young sexually active female out-patients without known pre-existing kidney disease or preceding manipulation of the urinary tract. Most cases present as acute cystitis ${ }^{5}$. There is however, a paucity of information on this organism in this part of the world. This study seeks to determine the incidence of $S$. saprophyticus as a cause of UTI in two patient populations. Ethical clearance was obtained from The University of Nigeria Teaching Hospital (UNTH), Enugu ethical committee. Informed consent was also obtained from the out-patients.

\section{Subjects}

\section{Subjects And Methods}

(i)In-patients: A total of 170 women aged between 13 and 45 years whose urine samples were submitted to the Microbiology laboratories of the UNTH, Park Lane Teaching Hospital, Enugu, Eastern Nigeria Medical Centre and two rural cottage hospitals in Iji-Nike and Owo-Emene having symptoms and signs suggestive of UTI. These patients were admitted into the various hospitals for one health problem or another. Of the 170 subjects, $22(12.9 \%)$ were in urinary catheter, while $19(11.2 \%)$ were renal patients. (ii) Out-patients: A total of 226 age-match controls with symptoms of frequency, urgency and dysuria which reported to the same hospitals were included in the study.

\section{Methodology}

Mid-stream urine samples were obtained from all the subjects in (i) in sterile containers, sent for laboratory studies in the University of Nigeria Departmental Laboratory of Medical laboratory Sciences Unit, Enugu campus between Oct 2010 and May 2012. Samples were processed within 1 hour of collection for:

(i) Physical and chemical examination, microbiology for cells like wbc, rbc etc using spun urine samples after taking off samples for culture.

(ii) Culture was done on Blood Agar and MacConkey agar (Oxoid) with well- mixed standardized platinum $(2 \mathrm{~mm})$ loop. Plates used were freshly prepared and well dried prior to inoculation. Specimens were incubated at $37^{\circ \mathrm{C}}$ aerobically for 24 hours. Organisms growing in pure culture with colony counts of $\geq 10^{5} / \mathrm{ml}$ forming units (CFU) per $\mathrm{ml}$ were regarded as significant bacteuria.

However, for staphylococcus and also for organisms in in-patients, counts of $10^{3}-10^{5}$ were accepted as significant. The staphylococci were gram- stained and tested for catalase, coagulase and other features according to standard bacteriological methods ${ }^{6}$ Coagulase negative staphylococci were identified to the species level as described by Kloos and Scieifer ${ }^{7}$. Briefly, coagulase negative staphylococci that were resistant to $5 \mu \mathrm{g}$ of Novobiocin per disk (Oxoid) were classified as S. saprophyticus if they were also urease positive. Urease production was tested by screening the isolates on urease agar (Difco). The S. saprophyticus were confirmed 
when they demonstrated a zone diameter of $<13 \mathrm{~mm}$ using $5 \mu \mathrm{g}$ disk of Novobiocin according to the recommendation of Monsen et $\mathrm{al}^{8}$.

The gram negative organisms were confirmed by a system of API- $20 \mathrm{E}^{6}$.

Statistical analysis: $\mathrm{P}$ values were read out from standard statistical table with the help of $\mathrm{t}$ values degrees of freedom. $T$ wave was calculated by student ' $t$ ' test formula. ' $\mathrm{X}{ }^{2}$ ' was applied for $\mathrm{t}$ value for comparison of findings of two graphs.

\section{Results:}

Of the 226 persons sampled in the out-patients, a total of 117 (51.8\%) were positive for UTI while 109 (48.2\%) yielded no significant growth. The difference, however, was not significant $(\mathrm{p}>0.05)$. The highest number of bacteria encountered in this group was Escherichia coli-64(54.7\%) followed by Staphylococcus saprophyticus-32 (27.4\%). (Table I).

For Staphylococcus saprophyticus, a total of 30 (93.8\%) isolates were from subjects below 30 years of age. This was statistically significant $(\mathrm{p}<0.05)$. Specifically, among the 30 subjects positive for $S$. saprophyticus, they ranged between 13 and 29 years.

Table 2 shows the result for in-patients. Of the 170 subjects included in the study, 98(57.6\%) were positive for UTI due to various types of bacteria. S. saprophyticus was the least causative organism with only $4(4.1 \%)$ in number.

In both out and in-patients, E. coli isolation were made from samples of subjects $>30$ years of age which when tested were found to be statistically significantly different $(\mathrm{p}<0.05)$. ( Tables $1 \& 2)$.

A clear seasonality pattern was observed in the isolation rate of $S$. saprophyticus. Of the 32 isolates from the out-patients, (Table 3), a clear distribution was observed in favor of the rainy season. No isolations were made at the peak of dry season in the area studied. Between July and September, 24 (75\%) of the positive cases for $S$. saprophyticus was recorded. Table 4 shows the distribution of positive cases for bacterial UTI according to some health modules.

\section{Disscusion}

The result has shown that $S$. saprophyticus is an important uropathogen in young women of reproductive age who are below 30 years of age in Enugu area of Nigeria. A total of $30(93.8 \%)$ were in this age group, while only $6.3 \%$ were recorded for the age group above 30 years in the out-patient group. This finding supports clearly the results of previous studies elsewhere. Hovelius and $\mathrm{Mardh}^{2}$ confirmed that the organism is a common cause of urinary tract infection in young women, while Farina et $\mathrm{al}^{3}$ observed its predominance in sexually active young women. In the age group $15-25$ years, the organism was demonstrated in no less than $42.3 \%{ }^{4}$. In their work in hospitalized women with signs of UTI, on the other hand, S. saprophyticus was a rare finding $(0.9 \%)$. In the current series among the hospitalized group, S. saprophyticus was the least encountered organism with $4.1 \%$ incidence.

The study of Nicole et $\mathrm{al}^{9}$ also showed that $S$ sapropyticus ratio to other coagulase negative staphylococcus was as follows: young age (median age, 22years versus 61years); ambulatory status (hospital out-patients), $86 \%$ versus $23 \%$ female sex ( $95 \%$ versus $52 \%$ ), thus supporting the findings in this study. The current study shows that another coagulase negative staphylococcus (S. epidemidis) accounted for $30.6 \%$ of infections, $4.1 \%$ with $S$. saprophyticus.

In the studies done in India by Kumari et $\mathrm{al}^{10}$, over a ten month study period on UTI due to a coagulse negative staphylococcus, the relative frequency of main organisms were as follows: S. epidermidis $-45.9 \%$ mainly from patients with indwelling catheters and complicated cases while S. saprophyticus $-34 \%$ was isolated from young female patients suffering from uncomplicated acute cystitis as against the $27.4 \%$ in this study. In the current series, out of the 20 subjects on urinary catheterization with UTI, $70 \%$ were due to $S$. epidemidis while none was positive for $S$. saprophyticus. This supports the statement that $\boldsymbol{S}$. saprophyticus is mainly a cause of community acquired UTI in young women as also reported in previous studies ${ }^{1-3}$ and not a cause of UTI in debilitating patients.

In this study, we have shown that $S$. saprophyticus is an important cause of UTI in ambulant women of reproductive age. The $27.4 \%$ incidence of S. saprophyticus UTI among out-patients in Enugu area of Nigeria is much higher than similar studies elsewhere. For example in Non Scotia Canada, it was $7.5 \%{ }^{1}$, in England ${ }^{11}$, $6.6 \%$ causing $10-20 \%$ of all UTIs in sexually active young women ${ }^{12,13}$ and $8.2 \%$ in Paraguay ${ }^{3}$. However, it is lower than the $42 \%$ recorded in similar population of women ${ }^{4}$ elsewhere. One can generally say that in young women, S. saprophyticus is responsible for 6 to $42 \%$ community UTI episodes in different parts of the world. S. saprophyticus was also generally reported as the $2^{\text {nd }}$ most common agent of UTI in a population, as shown in this study ${ }^{3,4,8,13}$. In these studies, E. coli was shown to be the most important in community UTI in young women. E. coli, Proteus murabilis and Klebsiella spp are often observed to cause uncomplicated UTI. More than $90 \%$ of UTIs in patients that have normal anatomic functions and structures are caused by E. coli while 10 - 
$20 \%$ are caused by $S$. saprophyticus and about $5 \%$ or less by other enterobacterceae or enterococci. Also in complicated cases of UTI such as resulting from anatomic obstructions or catheterization, the most common organisms include E. coli, klesiellae pneumonia, Proteus murabilis, Enterococcus spp and Pseudomonas aureginosa $^{13}$. In these studies, E. coli had an incidence of $53-72 \%$ in out-patients and $18-57 \%$ for in-patients.

A clear pattern of seasonality was also observed in the study period of 1 year in the current study of distribution of $S$. saprophyticus. Table 3 shows the research period span Jan and Dec 2012. Of the total number $32 S$. saprophyticus detected in the study, a total of $24(75 \%)$ were isolated between the months of July and September - the rainy season.

11. Studies elsewhere seem to align with this. Latham et al ${ }^{4,14}$ observed that $S$. saprophyticus infections occurred more frequently during late summer and early fall. Compared with other uropathogens, $S$. saprophyticus differs in seasonal variation and geographical distribution, being more frequent during late summer and early autumn ${ }^{15}$. However, Schneider and Riley reported from Australia, that although the monthly incidence fluctuated, no seasonality of $S$. saprophyticus UTI could be demonstrated in their studies.

Conclusively therefore, our data suggests that Staphylococcus saprophyticus is a uropathogen responsible for UTIs in young women of reproductive age (below 30years of age)in this part of Nigeria especially in the female out-patients, not usual in debilitating in-patients. This organism had been causally treated as saprophyte and contaminant in urine cultures and therefore ignored and not reported on. Physicians and Microbiologists must therefore be aware that S. saprophyticus is an important cause of UTIs in ambulant young women.

Finally, while $S$. saprophyticus was isolated from the genital tract of females aged 13 to 40 years in a study to investigate the source of these organisms ${ }^{6}$ it could not be isolated from the genital tracts of males aged 13 to 40 years ${ }^{17}$ or from the genital tract of females above $40 \mathrm{yrs}$.

Our data imply a relationship between these sexually active vulnerable age group, hormonal status and probably $S$. saprophyticus UTIs. This demands further detailed investigations.

Table 1

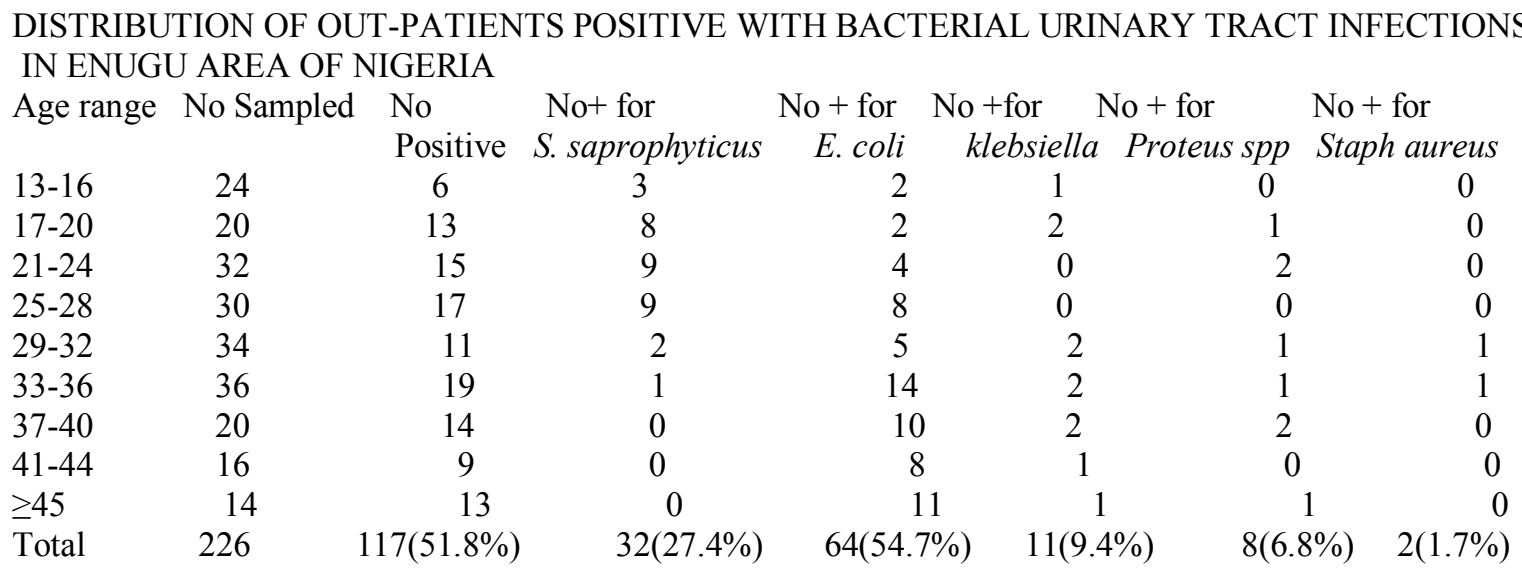

Table 2

DISTRIBUTION OF IN-PATIENTS POSITIVE WITH BACTERIAL URINARY TRACT INFECTIONS in ENUGU AREA OF NIGERIA

Age gp No sampled $\% \mathrm{No}+\% \mathrm{No}+$ with S. No + with $\mathrm{No}+$ with No + with No +with $\mathrm{S}$. No + with Yrs saprophyticus proteus spp E. coli Enterococcus epidemidis Ps spp

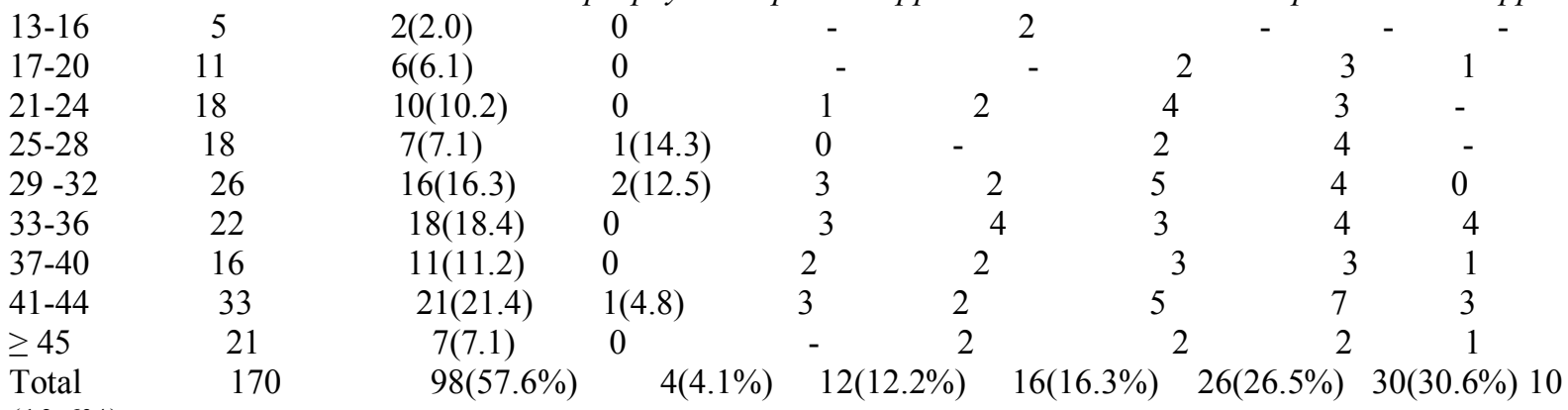

$(10.6 \%)$ 
Table 3

\begin{tabular}{ccc}
\multicolumn{2}{l}{$\begin{array}{l}\text { Isolation of S. saprophyticus according to seasonality } \\
\text { Year }\end{array}$ months } & No positive \\
2011 & Jan & nil 0 \\
& Feb & nil 0 \\
& March & nil 0 \\
April & $2(6.3 \%)$ \\
May & $1(3.1 \%)$ \\
June & $1(3.1 \%)$ \\
July & $4(12.5 \%)$ \\
August & $13(40.6 \%)$ \\
September & $7(27.9 \%)$ \\
October & $1(3.1 \%)$ \\
November & $1(3.1 \%)$ \\
December & $2(6.3 \%)$ \\
Total & 32
\end{tabular}

Table 4

BACTERIAL ISOLATES ACCORDING TO SOME OBSERVED HEALTH CONDITIONS Health Conditions No + S. saprophyticus S. epidermidis E. coli $\quad$ Ps spp Proteus spp Urinary

\begin{tabular}{|c|c|c|c|c|c|}
\hline Catheterization & 20 & 0 & 14 & 2 & 1 \\
\hline$(n=22)$ & $(90.9 \%)$ & & $(70 \%)$ & & \\
\hline $\begin{array}{l}\text { Renal patients } \\
4\end{array}$ & 14 & 1 & 2 & 4 & 1 \\
\hline $\begin{array}{l}(\mathrm{n}=19) \\
\text { Total } 41\end{array}$ & $\begin{array}{c}(73 \%) \\
34\end{array}$ & 1 & 16 & 6 & 2 \\
\hline
\end{tabular}

$(82.9 \%)$

\section{References}

[1]. Marne, J.J., Kwan, C., Noble, M. A., West, A. and Duffield, A. (1982). Staphylococcus saprophyticus as a cause of urinary tract infections J. Clin. Microbiol. 16(3):427-431.

[2]. Hovelius, B. Mardh and Bygren, P. (1979). Urinary tract infections caused by Staphylococcus saprophyticus: Recurences and complications. J. Urol. 122: 645-647.

[3]. Farina, N., Sanabria, R., Figueredo, L. , Ramos, L., and Samudico, M. (2005). Staphylococcus saprophyticus como patogeno urinario. Mem. Inst. Investig. Cienc. Sahid. 3(1): 31-33.

[4]. Wallmark, G., Arremark, I. and Talender, B. (1978). Staphylococcus saprophyticus: a frequent cause of acute urinary tract infection among female out-patients. J. Infect. Dis. 138 (6): 791-797.

[5]. Jordan, P.A., Iravani, A., Richard, G.A. and Baer, H. (1980). Urinary tract infection caused by Staphylococcus saprophyticus. J. Infect. Dis. 142 (4): 510-515.

[6]. Cheesbrough, M. (2000). Microbiological tests. In: District Laboratory Practice in Tropical Countries $.3^{\text {rd }}$ edition. Great Britain, Cambridge University Press. 266.

[7]. Kloos, W. E. and Schleifer, K. H. (1975). Simplified scheme for routine identification of human Staphylococcus aureus. J. Clin. Microbiol. 1: 82-88.

[8]. Mmsen, T. Ronnmark, M., Olafsson, C. and Wistrom, J. (1998).An inexpensive and reliable method for routine identification for Staphylococcal species. Eur. J. Clin. Mycrobiol. Infect. Dis. 17: 327-335.

[9]. Nicolle, L. E., Hoban S.A. and Harding G. K.(1983). Characteristics of coagulase negative staphylococci from urinary tract specimen. J. Clin. Microbiol. 17(2): 267-271.

[10]. Kumari, N., Rai, A. Jaiswal,C.P., Xess, and Shahi,S. K. (2001). Coagulase negative Staphylococcus as causative agents of urinary tract infections - prevalence and resistance status in IGIMS, patna. INDIAN Journal of Pathology and Microbiology. 44(4): 415-419.

[11]. Anderson, J. D., Clarke, M. F., Anderson, J. Isaac- Ranton, L. and McLonghhin, M. G.(1981). Urinary tract infections due to Staphylococcus saprophyticus biotype 3. Can. Med. Assoc. J. 124: 415-418.

[12]. Raz, P., Colodner, R. Kunim, C.M.(2005).Who are you - Staphylococcus saprophyticus? CID: 40: 896-898.

[13]. Paed, L., Maskell, R. and Morris, J. (1985). Staphylococcus saprophyticus as a urinary pathogen: a six-year prospective survey. British Medical Journal : 26(291): 1157-1159.

[14]. Latham, R. H., Running, K. and Stamm, W. E.(1983). Urinary tract infections in young adult women caused by Staphylococcus saprophyticus. JAMA, 250: 3063 - 3066. 45(5): 1561 -1564.

[15]. Widerstrom, M., Wistrom, J., Ferry, S., Karlsson,C. and Monsen, T. (2007). Molecular epidemiology of Staphylococcus saprophyticus isolated from women with uncomplicated acquired urinary tract infection. J. Clin. Microbiol.

[16]. Schneider, P. F. and Riley, T. V. (1996). Staphylococcus saprophyticus urinary tract infections: epidemiological data from Western Australia. European Journal of Epidemiology. 12(1): 51-54.

[17]. Gillespe, W. A., Sellin, M.A., Gill, P., Stephens, M., Tuckwell, L.A. and Hilton, A. L. (1978). Urinary tract infection in young women, with special reference to Staphylococcus saprophyticus. Journal of Clinical Pathology. 31: 348-350. 